\title{
PELABELAN TOTAL TITIK AJAIB PADA GRAF SIKLUS DENGAN BANYAK TITIK GENAP
}

\author{
RIRIN INDARWATI \\ Program Studi Matematika, \\ Fakultas Matematika dan Ilmu Pengetahuan Alam, Universitas Andalas, \\ Kampus UNAND Limau Manis Padang, Indonesia, \\ indarwatiririn@yahoo.com
}

\begin{abstract}
Abstrak. Misalkan $G$ adalah suatu graf dengan himpunan titik $V(G)$ dan himpunan sisi $E(G)$. Dalam hal ini $|V(G)|=v$ dan $|E(G)|=e$. Suatu graf $G$ merupakan graf total titik ajaib jika terdapat pemetaan bijektif $f$ dari $V(G) \cup E(G)$ ke himpunan $\{1,2, \cdots, v+e\}$ sedemikian sehingga untuk setiap titik $x$ dan setiap sisi $x y$ di $G$ berlaku $f(x)+\sum f(x y)=$ $k$, dengan $k$ adalah konstan. Pada jurnal ini penulis mengkaji tentang pelabelan total titik ajaib pada graf siklus dengan banyak titiknya genap.

Kata Kunci: Pelabelan total titik ajaib, graf siklus
\end{abstract}

\section{Pendahuluan}

Dalam teori graf, pelabelan menjadi topik yang banyak mendapat perhatian, karena model-model yang ada pada pelabelan graf berguna untuk aplikasi yang luas, seperti dalam masalah peta jaringan jalan raya, jaringan internet, sistem alamat jaringan komunikasi, dan desain sirkuit. Pelabelan merupakan pemetaan bijektif yang memasangkan unsur-unsur graf (titik atau sisi) dengan bilangan bulat positif yang disebut label. Pada suatu graf siklus dengan $e$ sisi dan $v$ titik dapat diberikan label pada titik dan sisi mulai dari angka 1 sampai $(v+e)$ sehingga apabila labellabel pada sisi yang saling bertetangga dan label titik yang terkait dengan sisi-sisi tersebut dijumlahkan, akan menghasilkan jumlah yang sama. Jumlah ini kemudian disebut sebagai bilangan ajaib (magic number) dan graf yang dihasilkan dikenal sebagai graf titik ajaib (vertex magic graph).

Untuk menentukan suatu graf titik ajaib tidaklah mudah, diperlukan teknik atau metode-metode tertentu dalam melabelkan suatu titik dan sisi sede- mikian sehingga didapatkan suatu bilangan ajaib yang sesuai pada masing-masing titik yang berbeda. Pada pelabelan total titik ajaib dari suatu graf siklus terdapat bilangan ajaib maksimum dan bilangan ajaib minimum. Metode pelabelan titik dan sisi (pelabelan total) berbeda-beda dalam suatu graf, bergantung pada banyaknya titik dan sisi pada graf tersebut. Pada graf siklus, jika banyaknya titik berjumlah genap maka penentuan label titik dan label sisi dilakukan dengan menyesuaikan jumlah seluruh label sisi terlebih dahulu. 


\section{Bilangan Ajaib Minimum pada Graf Siklus Genap}

Bilangan ajaib minimum pada pelabelan total titik ajaib terhadap graf siklus genap diberikan dalam dugaan (konjektur) berikut.

Dugaan 2.1. Misalkan graf $G$ adalah suatu graf siklus dengan banyak titik v bernilai genap, maka terdapat pelabelan total titik ajaib pada $G$ dengan bilangan ajaib minimum $k=\frac{5}{2} v+2$.

\subsection{Pengkonstruksian Label Sisi pada Graf Siklus $C_{2 n}$ dengan $n$ Bernilai Genap}

Jika $n$ bernilai genap, maka pengkonstruksian label sisinya adalah sebagai berikut.

$$
f\left(e_{i}\right)= \begin{cases}\frac{i+1}{2}, & i=1,3, \cdots, n+1, \\ 3 n, & i=2, \\ \frac{2 n+i}{2}, & i=4,6, \cdots, n, \\ \frac{2 n+i-1}{2}, & i=n+3, n+5, \cdots, 2 n-1, \\ \frac{i+2}{2}, & i=n+2, n+4, \cdots, 2 n\end{cases}
$$

Secara umum dikonstruksikan pelabelan titik untuk graf siklus adalah sebagai berikut.

$$
f\left(v_{i}\right)=\left\{\begin{array}{l}
k-f\left(e_{i}\right)-f\left(e_{2 n}\right), \quad i=1 \\
k-f\left(e_{i}\right)-f\left(e_{i}-1\right), i=2,3, \cdots, 2 n
\end{array}\right.
$$

Berikut adalah contoh untuk mengilustrasikan Dugaan 2.1 untuk graf siklus $C_{2 n}$ dengan $n$ genap, yaitu dengan mengambil $n=4$.

- Bila banyak titik adalah delapan , maka bilangan ajaib $(k)$ minimumnya adalah 22. Karena graf siklus $C_{m}$ dengan $m=2 n$, maka $n=4$.

- Kemudian sisinya akan dilabeli terlebih dahulu.

Untuk $i=1$, maka $f\left(e_{1}\right)=\frac{i+1}{2}=\frac{1+1}{2}=1$.

Untuk $i=2$, maka $f\left(e_{2}\right)=3 n=3(4)=12$.

Untuk $i=3$, maka $f\left(e_{3}\right)=\frac{i+1}{2}=\frac{3+1}{2}=2$.

Untuk $i=4$, maka $f\left(e_{4}\right)=\frac{2 n+i}{2}=\frac{2(4)+4}{2}=6$.

Untuk $i=5$, maka $f\left(e_{5}\right)=\frac{i+1}{2}=\frac{5+1}{2}=3$.

Untuk $i=6$, maka $f\left(e_{6}\right)=\frac{i+2}{2}=\frac{6+2}{2}=4$.

Untuk $i=7$, maka $f\left(e_{7}\right)=\frac{2 n+i-1}{2}=\frac{2(4)+7-1}{2}=7$.

Untuk $i=8$, maka $f\left(e_{8}\right)=\frac{i+2}{2}=\frac{8+2}{2}=5$.

- Selanjutnya akan dicari nilai dari label titik.

Untuk $i=1$, maka $f\left(v_{1}\right)=k-f\left(e_{1}\right)-f\left(e_{8}\right)=22-1-5=16$.

Untuk $i=2$, maka $f\left(v_{2}\right)=k-f\left(e_{2}\right)-f\left(e_{1}\right)=22-12-1=9$.

Untuk $i=3$, maka $f\left(v_{3}\right)=k-f\left(e_{3}\right)-f\left(e_{2}\right)=22-2-12=8$.

Untuk $i=4$, maka $f\left(v_{4}\right)=k-f\left(e_{4}\right)-f\left(e_{3}\right)=22-6-2=14$.

Untuk $i=5$, maka $f\left(v_{5}\right)=k-f\left(e_{5}\right)-f\left(e_{4}\right)=22-3-6=13$.

Untuk $i=6$, maka $f\left(v_{6}\right)=k-f\left(e_{6}\right)-f\left(e_{5}\right)=22-4-3=15$.

Untuk $i=7$, maka $f\left(v_{7}\right)=k-f\left(e_{7}\right)-f\left(e_{6}\right)=22-7-4=11$.

Untuk $i=8$, maka $f\left(v_{8}\right)=k-f\left(e_{8}\right)-f\left(e_{7}\right)=22-7-5=10$. 
Berdasarkan langkah-langkah yang telah dilakukan maka diperoleh pelabelan graf $G$ seperti Gambar 2.1 berikut.

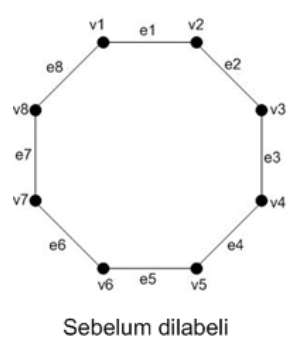

Sebelum dilabeli

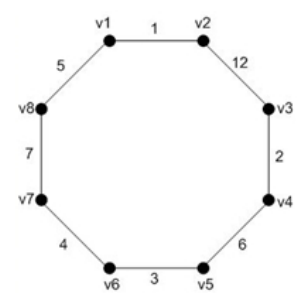

Setelah sisi-sisinya dilabeli

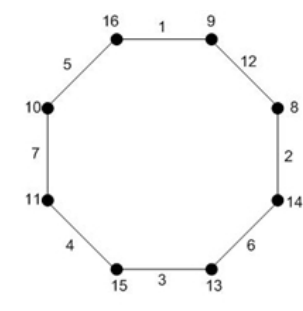

Setelah sisi-sisi dan titik-titiknya dilabeli

Gambar 2.1. Graf siklus $C_{8}$ dan $k$ minimum 22

\subsection{Pengkonstruksian Label Sisi pada Graf Siklus $C_{2 n}$ dengan $n$ Bernilai Ganjil}

Jika $n$ bernilai ganjil, maka pengkonstruksian label sisinya adalah sebagai berikut.

$$
f\left(e_{i}\right)= \begin{cases}\frac{i+1}{2}, & i=1,3, \cdots, n, \\ 3 n, & i=2, \\ \frac{2 n+i+2}{2}, & i=4,6, \cdots, n-1, \\ \frac{n+3}{2}, & i=n+1, \\ \frac{2 n+i}{2}, & i=n+3, n+5, \cdots, 2 n-2, \\ \frac{i+3}{2}, & i=n+2, n+4, \cdots, 2 n-1, \\ n+2, & i=2 n .\end{cases}
$$

Diberikan contoh untuk mengilustrasikan Dugaan 2.1 untuk graf siklus $C_{2 n}$ dengan $n$ ganjil, yaitu dengan mengambil $n=3$.

- Bila banyak titik adalah enam, maka bilangan ajaib $(k)$ minimumnya adalah 17. Karena graf siklus $C_{m}$ dengan $m=2 n$, maka $n=3$.

- Kemudian sisinya akan dilabeli terlebih dahulu.

Untuk $i=1$, maka $f\left(e_{1}\right)=\frac{i+1}{2}=\frac{1+1}{2}=1$.

Untuk $i=2$, maka $f\left(e_{2}\right)=3 n=3(3)=9$.

Untuk $i=3$, maka $f\left(e_{3}\right)=\frac{i+1}{2}=\frac{3+1}{2}=2$.

Untuk $i=4$, maka $f\left(e_{4}\right)=\frac{n+3}{2}=\frac{3+3}{2}=3$.

Untuk $i=5$, maka $f\left(e_{5}\right)=\frac{i+3}{2}=\frac{5+3}{2}=4$.

Untuk $i=6$, maka $f\left(e_{6}\right)=n+2=3+2=5$.

- Selanjutnya akan dicari nilai dari label titik.

Untuk $i=1$, maka $f\left(v_{1}\right)=k-f\left(e_{1}\right)-f\left(e_{6}\right)=17-1-5=11$.

Untuk $i=2$, maka $f\left(v_{2}\right)=k-f\left(e_{2}\right)-f\left(e_{1}\right)=17-9-1=7$.

Untuk $i=3$, maka $f\left(v_{3}\right)=k-f\left(e_{3}\right)-f\left(e_{2}\right)=17-2-9=6$.

Untuk $i=4 \mathrm{t}$, maka $f\left(v_{4}\right)=k-f\left(e_{4}\right)-f\left(e_{3}\right)=17-3-2=12$.

Untuk $i=5$, maka $f\left(v_{5}\right)=k-f\left(e_{5}\right)-f\left(e_{4}\right)=17-4-3=10$.

Untuk $i=6$, maka $f\left(v_{6}\right)=k-f\left(e_{6}\right)-f\left(e_{5}\right)=17-5-4=8$. 
Berdasarkan langkah-langkah yang telah dilakukan maka diperoleh pelabelan graf $G$ seperti Gambar 2.2 berikut.

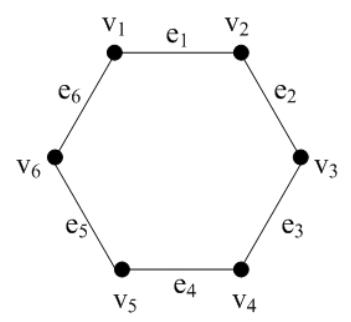

Sebelum dilabeli

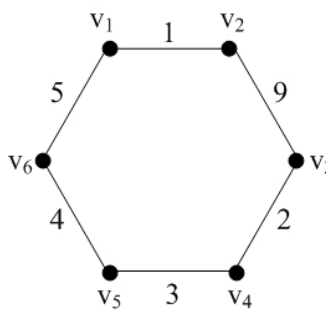

Setelah sisi-sisinya dilabeli

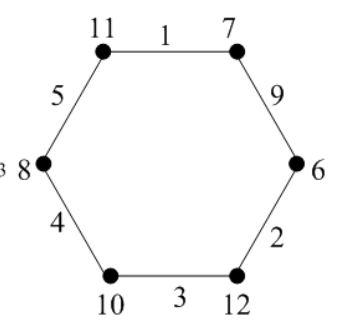

Setelah sisi-sisi dan titiktitiknya dilabeli

Gambar 2.2. Graf siklus $C_{6}$ dan $k$ minimum 17

\section{Bilangan Ajaib Maksimum pada Graf Siklus Genap}

Selanjutnya, akan dikonstruksi suatu graf titik ajaib dengan bilangan ajaib maksimum untuk graf siklus genap. Hal ini diberikan dalam Teorema 3.1 berikut.

Teorema 3.1. Misalkan $G$ merupakan graf siklus dengan $v$ titik dimana $v$ bernilai genap. Jika Dugaan 2.1 terpenuhi, maka terdapat suatu pelabelan total titik ajaib untuk $G$ dengan bilangan ajaib maksimumnya $k=\frac{7}{2} v+1$.

Bukti. Untuk mendapatkan nilai $k$ yang minimum pada Dugaan 2.1 dengan $v$ bernilai genap, sisi dilabeli dengan bilangan-bilangan $1,2,3, \cdots, v-1, v+\frac{v}{2}$. Untuk mendapatkan nilai $k$ yang maksimum dengan $v$ bernilai genap, sisi dilabeli dengan bilangan sebagai berikut : $2 v, 2 v-1, \cdots, v+2, v+1-\frac{v}{2}$.

Nilai-nilai tersebut diperoleh dari $2 v+1$ dikurangi dengan label pada sisi dalam pelabelan minimum. Dengan menggunakan nilai $k$ yang maksimum, kita dapat mengurangkan jumlah dari dua sisi untuk melabeli setiap titik.

\subsection{Pengkonstruksian Label Sisi pada Graf Siklus $C_{2 n}$ dengan $n$ Bernilai Genap}

Jika $n$ bernilai genap, maka pengkonstruksian label sisinya adalah sebagai berikut.

$$
f\left(e_{i}\right)= \begin{cases}2 v-\frac{i+1}{2}+1, & i=1,3, \cdots, n+1, \\ 2 v-3 n+1, & i=2, \\ 2 v-\frac{2 n+i}{2}+1, & i=4,6, \cdots, n, \\ 2 v-\frac{2 n+i-1}{2}+1, & i=n+3, n+5, \cdots, 2 n-1, \\ 2 v-\frac{i+2}{2}+1, & i=n+2, n+4, \cdots, 2 n .\end{cases}
$$

Diberikan contoh untuk mengilustrasikan Teorema 3.1 untuk graf siklus $C_{2 n}$ dengan $n$ genap, yaitu dengan mengambil $n=4$. 
- Bila banyak titik adalah delapan, maka bilangan ajaib $(k)$ maksimumnya adalah 29. Karena graf siklus $C_{m}$ dengan $m=2 n$, maka $n=4$.

- Kemudian sisinya akan dilabeli terlebih dahulu.

Untuk $i=1$, maka $f\left(e_{1}\right)=2 v-\frac{i+1}{2}+1=2(8)-\frac{1+1}{2}+1=16$.

Untuk $i=2$, maka $f\left(e_{2}\right)=2 v-3 n+1=2(8)-3(4)+1=5$.

Untuk $i=3$, maka $f\left(e_{3}\right)=2 v-\frac{i+1}{2}+1=2(8)-\frac{3+1}{2}+1=15$.

Untuk $i=4$, maka $f\left(e_{4}\right)=2 v-\frac{2 n+i}{2}+1=2(8)-\frac{2(4)+4}{2}+1=11$.

Untuk $i=5$, maka $f\left(e_{5}\right)=2 v-\frac{i+1}{2}+1=2(8)-\frac{5+1}{2}+1=14$.

Untuk $i=6$, maka $f\left(e_{6}\right)=2 v-\frac{i+2}{2}+1=2(8)-\frac{6+2}{2}+1=13$.

Untuk $i=7$, maka $f\left(e_{7}\right)=2 v-\frac{2 n+i-1}{2}+1=2(8)-\frac{2(4)+7-1}{2}+1=10$.

Untuk $i=8$, maka $f\left(e_{8}\right)=2 v-\frac{i+2}{2}+1=2(8)-\frac{8+2}{2}+1=12$.

- Selanjutnya akan dicari nilai dari label titik.

Untuk $i=1$, maka $f\left(v_{1}\right)=k-f\left(e_{1}\right)-f\left(e_{8}\right)=29-16-12=1$.

Untuk $i=2$, maka $f\left(v_{2}\right)=k-f\left(e_{2}\right)-f\left(e_{1}\right)=29-5-16=8$.

Untuk $i=3$, maka $f\left(v_{3}\right)=k-f\left(e_{3}\right)-f\left(e_{2}\right)=29-15-5=9$.

Untuk $i=4$, maka $f\left(v_{4}\right)=k-f\left(e_{4}\right)-f\left(e_{3}\right)=29-11-15=3$.

Untuk $i=5$, maka $f\left(v_{5}\right)=k-f\left(e_{5}\right)-f\left(e_{4}\right)=29-14-11=4$.

Untuk $i=6$, maka $f\left(v_{6}\right)=k-f\left(e_{6}\right)-f\left(e_{5}\right)=29-13-14=2$.

Untuk $i=7$, maka $f\left(v_{7}\right)=k-f\left(e_{7}\right)-f\left(e_{6}\right)=29-10-13=6$.

Untuk $i=8$, maka $f\left(v_{8}\right)=k-f\left(e_{8}\right)-f\left(e_{7}\right)=29-12-10=7$.

Berdasarkan langkah-langkah yang telah dilakukan maka diperoleh pelabelan graf $G$ seperti Gambar 3.1 berikut.

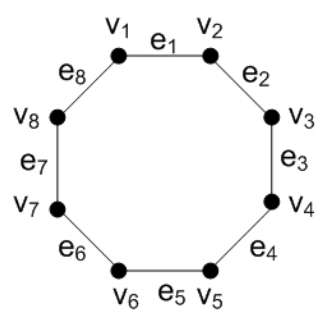

Sebelum dilabeli

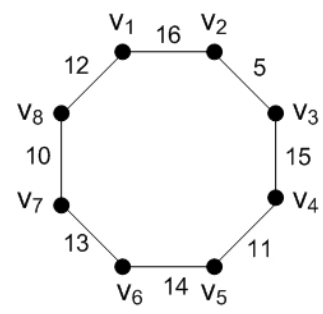

Seelah sisi-sisinya dilabeli

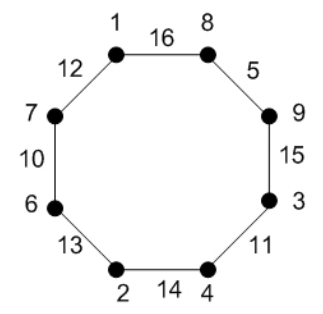

Setelah sisi-sisi dan titik-titiknya dilabeli 


\subsection{Pengkonstruksian Label Sisi pada Graf Siklus $C_{2 n}$ dengan $n$ Bernilai Ganjil}

Jika $n$ bernilai ganjil, maka pengkonstruksian label sisinya adalah sebagai berikut.

$$
f\left(e_{i}\right)= \begin{cases}2 v-\frac{i+1}{2}+1, & i=1,3, \cdots, n, \\ 2 v-3 n+1, & i=2, \\ 2 v-\frac{2 n+i+2}{2}+1, & i=4,6, \cdots, n-1, \\ 2 v-\frac{n+3}{2}+1, & i=n+1, \\ 2 v-\frac{2 n+i}{2}+1, & i=n+3, n+5, \cdots, 2 n-2, \\ 2 v-\frac{i+3}{2}+1, & i=n+2, n+4, \cdots, 2 n-1, \\ 2 v-(n+2)+1, & i=2 n .\end{cases}
$$

Diberikan contoh untuk mengilustrasikan Teorema 3.1 dengan $n$ ganjil, yaitu dengan mengambil $n=3$.

- Bila banyak titik adalah enam, maka bilangan ajaib $(k)$ maksimumnya adalah 22. Karena graf siklus $C_{m}$ dengan $m=2 n$, maka $n=3$.

- Kemudian sisinya akan dilabeli terlebih dahulu.

Untuk $i=1$, maka $f\left(e_{1}\right)=2 v-\frac{i+1}{2}+1=2(6)-\frac{1+1}{2}+1=12$.

Untuk $i=2$, maka $f\left(e_{2}\right)=2 v-3 n+1=2(6)-3(3)+1=4$.

Untuk $i=3$, maka $f\left(e_{3}\right)=2 v-\frac{i+1}{2}+1=2(6)-\frac{3+1}{2}+1=11$.

Untuk $i=4$, maka $f\left(e_{4}\right)=f\left(e_{n+1}\right)=2 v-\frac{n+3}{2}+1=2(6)-\frac{3+3}{2}+1=10$.

Untuk $i=5$, maka $f\left(e_{5}\right)=f\left(e_{n+2}\right)=2 v-\frac{i+3}{2}+1=2(6)-\frac{5+3}{2}+1=9$.

Untuk $i=6$, maka $f\left(e_{6}\right)=f\left(e_{2 n}\right)=2 v-(n+2)=2(6)-(3+2)+1=8$.

- Selanjutnya akan dicari nilai dari label titik.

Untuk $i=1$, maka $f\left(v_{1}\right)=k-f\left(e_{1}\right)-f\left(e_{6}\right)=22-12-8=2$.

Untuk $i=2$, maka $f\left(v_{2}\right)=k-f\left(e_{2}\right)-f\left(e_{1}\right)=22-4-12=6$.

Untuk $i=3$, maka $f\left(v_{3}\right)=k-f\left(e_{3}\right)-f\left(e_{2}\right)=22-11-4=7$.

Untuk $i=4$, maka $f\left(v_{4}\right)=k-f\left(e_{4}\right)-f\left(e_{3}\right)=22-10-11=1$.

Untuk $i=5$, maka $f\left(v_{5}\right)=k-f\left(e_{5}\right)-f\left(e_{4}\right)=22-9-10=3$.

Untuk $i=6$, maka $f\left(v_{6}\right)=k-f\left(e_{6}\right)-f\left(e_{5}\right)=22-8-9=5$.

Berdasarkan langkah-langkah yang telah dilakukan maka diperoleh pelabelan graf $G$ seperti pada Gambar 3.2 berikut.

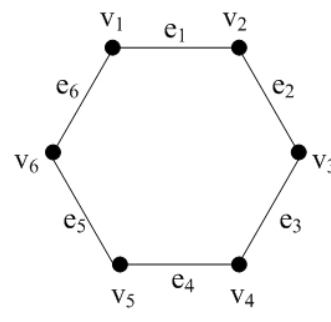

Sebelum dilabeli

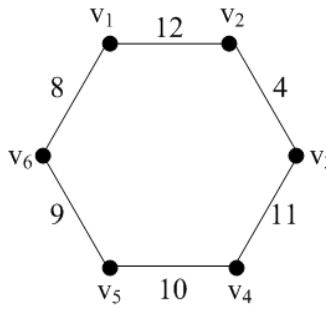

Setelah sisi-sisinya dilabeli

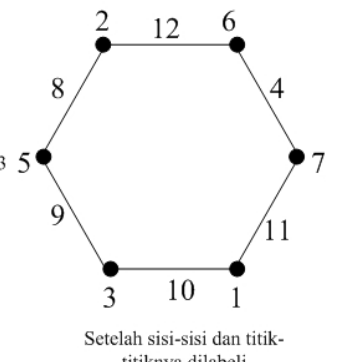

titiknya dilabeli

Gambar 3.2. Graf siklus $C_{6}$ dan $k$ maksimum 22 


\section{Kesimpulan}

Berdasarkan pembahasan dapat disimpulkan bahwa untuk melabelkan graf siklus yang banyak titiknya genap menjadi pelabelan total titik ajaib, suatu graf siklus dapat dilabeli berdasarkan bilangan ajaib maksimum atau minimum. Bilangan ajaib yang diperoleh bergantung pada teknik pelabelan graf siklus yang dilakukan, yaitu, untuk pelabelan graf siklus berdasarkan bilangan ajaib minimum, maka diperoleh bilangan ajaib $k=\frac{5}{2} v+2$, sedangkan untuk pelabelan graf siklus berdasarkan bilangan ajaib maksimum, diperoleh bilangan ajaib $k=\frac{7}{2} v+1$.

\section{Ucapan Terima kasih}

Penulis mengucapkan terima kasih kepada Ibu Dr. Lyra Yulianti, Ibu Hazmira Yozza M.Si dan Bapak Drs. Syafruddin M.Si yang telah memberikan masukan dan saran sehingga makalah ini dapat diselesaikan dengan baik.

\section{Daftar Pustaka}

[1] Bondy, J. A. and Murty, U.S.R. 1976. Graph Theory with Applications. London : The Macmillan Press Ltd.

[2] Cunningham, D. 2004. Vertex Magic. Elektronic Journal of Undergraduate Mathematics. 9 : $1-20$

[3] J.A. MacDougall, Mirka Miller, Slamin, W.D Wallis. 2004. Vertex Magic Total Labelings of Graphs. 